\title{
Pyroglutamated Apelin-13 Inhibits Lipopolysaccharide-Induced Production of Pro-Inflammatory Cytokines in Murine Macrophage J774.1 Cells
}

\author{
Shigeyuki Obara ${ }^{1,2}$, Sumio Akifusa ${ }^{3 *}$, Wataru Ariyoshi², Toshinori Okinaga ${ }^{2}$, \\ Michihiko Usui' ${ }^{1}$, Keisuke Nakashima1, Tatsuji Nishihara² \\ ${ }^{1}$ Division of Periodontology, Department of Oral Function, Kyushu Dental University, Fukuoka, \\ Japan \\ ${ }^{2}$ Division of Infections and Molecular Biology, Department of Health Promotion, Kyushu Dental University, \\ Fukuoka, Japan \\ ${ }^{3}$ Department of Oral Health Management, Kyushu Dental University, Fukuoka, Japan \\ Email: ${ }^{*}$ r11akifusa@fa.kyu-dent.ac.jp
}

Received 31 March 2014; revised 26 April 2014; accepted 4 May 2014

Copyright (C) 2014 by authors and Scientific Research Publishing Inc.

This work is licensed under the Creative Commons Attribution International License (CC BY).

http://creativecommons.org/licenses/by/4.0/

(c) (i) Open Access

\section{Abstract}

Apelin, recently identified as an endogenous ligand of the orphan G protein-coupled receptor APJ, has multiple pathophysiological properties. In the present study, we investigated whether pyroglutamated apelin-13 ([Pyr1]-apelin-13), the most highly active isoform among the mature apelin peptide family, modulates the effect of bacterial lipopolysaccharide (LPS) on cytokine induction in a murine macrophage-like cell line, J774.1 cells. J774.1 cells expressed the APJ protein in a stationary state, and the expression of APJ was not affected by LPS stimulation. No significant effect of [Pyr1]-apelin-13 treatment alone was observed on the proliferation or cytokine production of J774.1 cells in the stationary state. However, prior to LPS stimulation, pretreatment with [Pyr1]apelin-13 for $16 \mathrm{~h}$ significantly diminished mRNA expression and protein secretion of inflammatory cytokine interleukin-6, which was confirmed by RT-PCR and ELISA, respectively. Western blot analysis revealed that the phosphorylation of p38 mitogen-activated protein kinase and c-Jun $\mathrm{N}$-terminal kinase, but not extracellular signal-regulated kinase, which was induced by LPS, significantly decreased in [Pyr1]-apelin-13-pretreated J774.1 cells compared with untreated cells. These observations suggest that [Pyr1]-apelin-13 functions as a negative regulator of LPS-mediated pro-inflammatory responses in macrophages.

"Corresponding author.

How to cite this paper: Obara, S., et al. (2014) Pyroglutamated Apelin-13 Inhibits Lipopolysaccharide-Induced Production of Pro-Inflammatory Cytokines in Murine Macrophage J774.1 Cells. Modern Research in Inflammation, 3, 59-66.

http://dx.doi.org/10.4236/mri.2014.32007 


\section{Keywords}

\section{Apelin, Macrophage, Inflammation}

\section{Introduction}

APJ, which is highly conserved in vertebrates, is similar to the angiotensin II type 1 receptor, but does not bind angiotensin II. Apelin, originally identified in bovine stomach extracts, is an endogenous ligand of the orphan Gi-G protein-coupled receptor APJ. Apelin has several mature forms. Apelin is initially synthesised as a 77amino acid pre-propeptide that is cleaved to yield bioactive peptides of 36, 17, 13 and 12 amino acids in length [1]. These mature forms of apelin lack cysteine residues, suggesting that they are monomeric [2]. Among the active forms of the apelin family, the pyroglutamated isoform of apelin ([Pyr1]-apelin-13) has the highest abundance and activity based on its resistance to degradation [1]. The sequence of the C-terminal apelin-13-peptide is conserved in most vertebrates, suggestive of evolutionary conservation and having an important function [3].

APJ and apelin are found in a wide variety of tissues, including brain, heart, lung, kidney, gastrointestinal tract, retina and mammary glands [4]-[7]. Growing evidence suggests that apelin has many physiological functions, such as fluid homeostasis, food intake, cell proliferation, blood pressure regulation, cardiovascular function, angiogenesis and glucose utilization. Thus, the apelinergic system plays an important role in central and peripheral homeostatic regulation [8]-[11].

Apelin is mainly produced and secreted by adipocytes and stimulates glucose uptake through the PI3K/AKT pathway [12]. In clinical studies, serum apelin levels were positively correlated with body mass index, and the levels increased in patients with impaired glucose intolerance or type 2 diabetes [13] [14]. Immunologically, apelin has been shown to suppress cytokine production by mouse spleen cells in response to T-cell receptor/CD3 cross-linking [15]. Apelin inhibits cholinergic activity by decreasing acetylcholine synthesis and release through the downregulation of choline acetyltransferase mRNA expression in the leukemic T-cell line, MOLT-3 [16]. Although immunological studies on isoforms of the apelin peptide have been performed, the role of apelin in host defense against bacterial pathogens remains unclear.

In the present study, we investigated the effect of [Pyr1]-apelin-13 on immunological and inflammatory reactions in lipopolysaccharide (LPS)-stimulated J774.1 murine macrophage-like cells.

\section{Methods}

\subsection{Reagents and Antibodies}

Synthetic pyroglutaminated apelin-13 ([Pyr-1]-apelin-13) was purchased from the Peptide Institute, Inc. (Osaka, Japan). LPS derived from Escherichia coli (serotype O111:B4) and anti- $\beta$-actin monoclonal antibody were obtained from Sigma-Aldrich (St. Louis, MO, USA). Anti-mouse APJ antibody was acquired from GeneTex, Inc. (Irvine, CA, USA). Anti-mouse phosphorylated p38 mitogen-activated protein kinase (p-p38 MAPK), phosphorylated p44/42 MAPK (p-Erk1/2) and phosphorylated stress-activated protein kinase/Jun-amino-terminal kinase (p-SAPK/JNK) antibodies were purchased from Cell Signaling Technology, Inc. (Boston, MA, USA). 3-(4,5dimethyl-2-thiazolyl)-2,5-diphenyl-2H-tetrazolium bromide (MTT) was purchased from Molecular Probes (Carlsbad, CA, USA).

\subsection{Cell Culture}

The murine macrophage cell line J774.1 was obtained from the Japanese Cancer Research Resources Bank (Tokyo, Japan) and murine macrophage cell line RAW264.7 was obtained from the American Type Culture Collection (Manassas, VA, USA). J774.1 and RAW264.7 were maintained at $37^{\circ} \mathrm{C}$ in RPMI-1640 medium (Gibco-BRL, Grand Island, NY, USA) supplemented with $10 \%$ heat-inactivated fetal bovine serum (FBS), penicillin $\mathrm{G}\left(100 \mathrm{U} \cdot \mathrm{mL}^{-1}\right)$ and streptomycin $\left(100 \mu \mathrm{g} \cdot \mathrm{mL}^{-1}\right)$ in an atmosphere of $5 \% \mathrm{CO}_{2}$ in air. Cells $\left(2 \times 10^{5}\right.$ cells $\left.\cdot \mathrm{mL}^{-1}\right)$ were then cultured with RPMI-1640 medium containing 5\% FBS in a 6-well plastic plate and preincubated with [Pyr-1]-apelin-13 for $16 \mathrm{~h}$. Thereafter, cells were cultured with or without LPS $\left(10 \mathrm{ng} \cdot \mathrm{mL}^{-1}\right)$, after which samples were harvested for assays. 


\subsection{Quantitative Real-Time Reverse Transcription (RT)-PCR}

Total RNA was isolated from cells using the RNeasy ${ }^{\circledR}$ Mini Kit (Qiagen, Valencia, CA, USA). Samples were reverse transcribed with q-Script cDNA Supermix reagents (Quanta BioSciences, Gaithersburg, MD, USA) and amplified for $30 \mathrm{~min}$ at $42^{\circ} \mathrm{C}$. For real-time RT-PCR, the PCR products were detected using FAST SYBR ${ }^{\circledR}$ Green Master Mix (Applied Biosystems, Foster City, CA, USA) using the following primer sequences: GAPDH forward, 5'-GACGGCCGCATCTTCTTGA-3' and reverse, 5'-CACACCGACCTTCACCATTTT-3'; IL-1 $\beta$ forward, 5'-AGTTGACGGACCCCAAAAGA-3' and reverse, 5'-GGACAGCCCAGGTCAAAGG-3'; and IL-6 forward, 5'-CCACGGCCTTCCCTACTTC-3' and reverse, 5'-TTGGGAGTGGTATCCTCTGTGA-3'. Thermal cycling and fluorescence detection were performed using a StepOne ${ }^{\mathrm{TM}}$ Real Time PCR System (Applied Biosystems). The mRNA expression levels were quantified according to the ${ }^{\Delta \Lambda} \mathrm{CT}$ method, normalised against GAPDH expression and presented relative to control levels.

\subsection{Western Blot Analysis}

Total protein was extracted using Cell Lysis Buffer (Cell Signaling Technology, Inc.) containing a protease inhibitor cocktail (Thermo Fisher Scientific, Waltham, MA, USA). Protein concentrations ware determined using the DCтм Protein Assay Kit (Bio-Rad, Hercules, CA, USA). The same amounts of total protein were loaded in each lane for sodium dodecyl sulphate-polyacrylamide gel electrophoresis (SDS-PAGE) using $12.5 \%$ gels, and were then transferred to polyvinylidene difluoride membranes (Millipore Corp., Bedford, MA, USA). After blocking for $30 \mathrm{~min}$ in Blocking One (Nacalai Tesque, Inc., Tokyo, Japan), the membranes were incubated overnight with diluted primary antibodies at $4^{\circ} \mathrm{C}$. Antibody binding was detected using horseradish peroxidaseconjugated secondary antibodies. Chemiluminenscence was produced using ECL Prime Western Blotting Reagent (GE Healthcare, Little Chalfont, UK) and detected digitally with GelDoc XR Plus (Bio-Rad).

\subsection{Determination of IL-6 Concentrations}

A sandwich ELISA was performed using the mouse IL-6 ELISA kit (Thermo Fisher Scientific) according to the manufacturer's protocol. Conditioned media were diluted between 1:10 and 1:50.

\subsection{Statistical Analysis}

Statistical analysis was conducted with JMP software, version 9.0.2. Data are presented as means \pm SD. Groups were compared using the two-tailed Students $t$-test for parametric data. A value of $P<0.05$ was considered statistically significant.

\section{Results}

\subsection{Expression of the Apelin Receptor APJ in Macrophage Cell Lines}

To investigate the immune function of apelin in macrophages, we first confirmed the expression of APJ in wellknown macrophage cell lines, J774.1 and RAW 264.7 cells. Apelin administration had no effect on cell proliferation based on MTT assays (data not shown). Western blotting analysis revealed that both cell lines expressed APJ protein in their stationary state (Figure 1). Treatment with [Pyr1]-apelin-13 for $16 \mathrm{~h}$ had no effect on APJ expression. In addition, LPS administration did not affect the amount of APJ expression in the two cell lines.

\subsection{Effect of Apelin on LPS-Induced mRNA and Protein Expression of Pro-Inflammatory Cytokines}

We next examined the effect of [Pyr1]-apelin-13 on the LPS-stimulated inflammatory response in J774.1 cells. $\mathrm{J} 774.1$ cells were treated with $1 \mu \mathrm{M}$ [Pyr1]-apelin-13 for $16 \mathrm{~h}$ and were then administered $10 \mathrm{ng} \cdot \mathrm{mL}^{-1} \mathrm{LPS}$ for an additional 2 - $4 \mathrm{~h}$. Real-time RT-PCR analysis revealed that pretreatment with [Pyr1]-apelin-13 decreased LPS-induced IL-1 $\beta$ and IL-6 mRNA expression (Figure 2(a) and Figure 2(b), respectively). The LPS-induced expression of IL- $1 \beta$ and IL-6 mRNA were suppressed by $65.2 \% \pm 4.2 \%$ and $63.3 \% \pm 2.6 \%$, respectively, by [Pyr1]-apelin-13 pretreatment in J774.1 cells. In addition, ELISA analysis revealed that pretreatment with [Pyr1]-apelin-13 significantly suppressed LPS-induced IL-6 secretion from J774.1 cells (Figure 3). These re- 


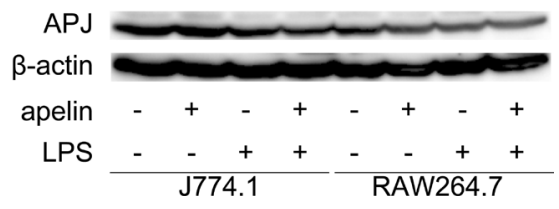

Figure 1. Expression of APJ was examined by Western blotting analysis in J774.1 and RAW264.7 cells. Cells were pretreated with or without [Pyr-1]-apelin-13 $(1 \mu \mathrm{M})$ overnight and then stimulated with LPS (10 $\mathrm{ng} \cdot \mathrm{mL}^{-1}$ ) for $6 \mathrm{~h}$. Whole lysates were immunoblotted with anti-APJ antibody. The aliquots contained equivalent amounts of protein, which was verified by Western blotting for $\beta$-actin.

(a)

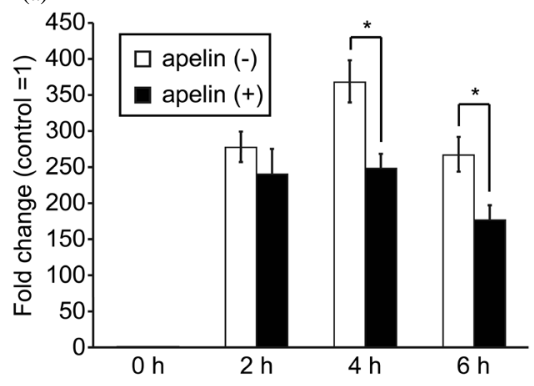

(b)

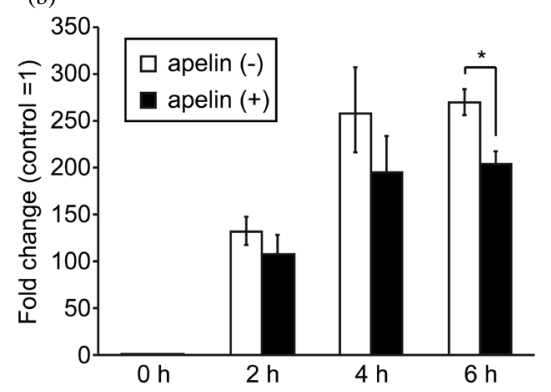

Figure 2. Effect of apelin on LPS-induced IL-1 $\beta$ and IL-6 mRNA expression in J774.1 cells. Cells were pretreated with or without [Pyr-1]-apelin-13 $(1 \mu \mathrm{M})$ overnight and then stimulated with LPS (10 ng. $\mathrm{mL}^{-1}$ ) for the indicated times. PCR amplification was performed using primers specific for IL-1 $\beta$ (a), IL-6 (b) and GAPDH. Values are expressed as fold change and compared with untreated control. Values shown represent the mean $\pm \mathrm{SD}$ of results from triplicate cultures. ${ }^{*} P<0.01$, two-tailed Students $t$-test.

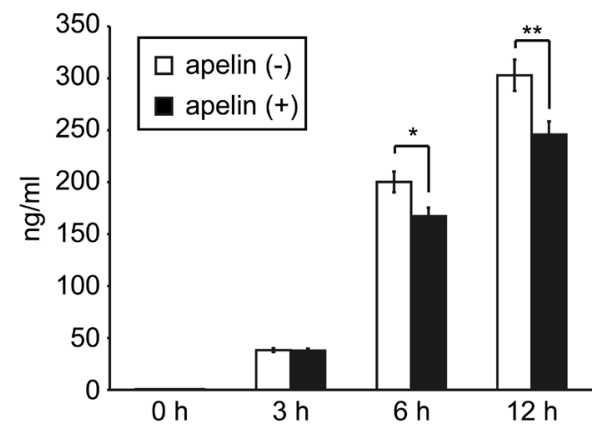

Figure 3. Effect of apelin on LPS-induced IL-6 protein secretion in J774.1 cells. Cells were pretreated with or without [Pyr-1]-apelin$13(1 \mu \mathrm{M})$ overnight and then stimulated with LPS $\left(10 \mathrm{ng} \cdot \mathrm{mL}^{-1}\right)$ for the indicated times. The concentration of IL-6 in the supernatants of cultured J774.1 cells was analysed by ELISA. The data shown represent the mean \pm SD of results from triplicate cultures. ${ }^{*} P<0.05,{ }^{* *} P$ $<0.01$, two-tailed Students $t$-test.

sults strongly suggest that [Pyr1]-apelin-13 has anti-inflammatory properties by inhibiting IL-6 expression in macrophages. 
(a)

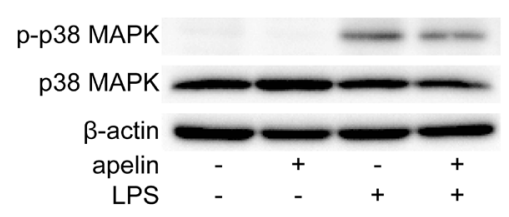

(b)

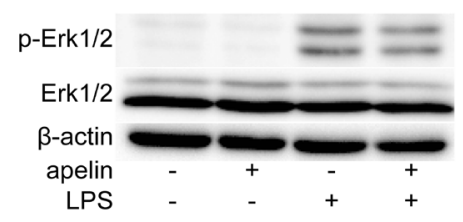

(c)

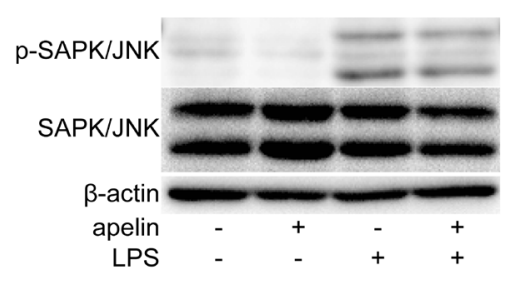

(d)

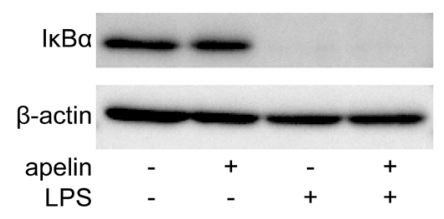

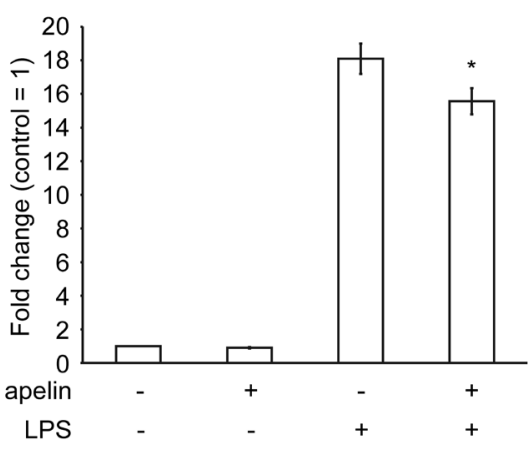
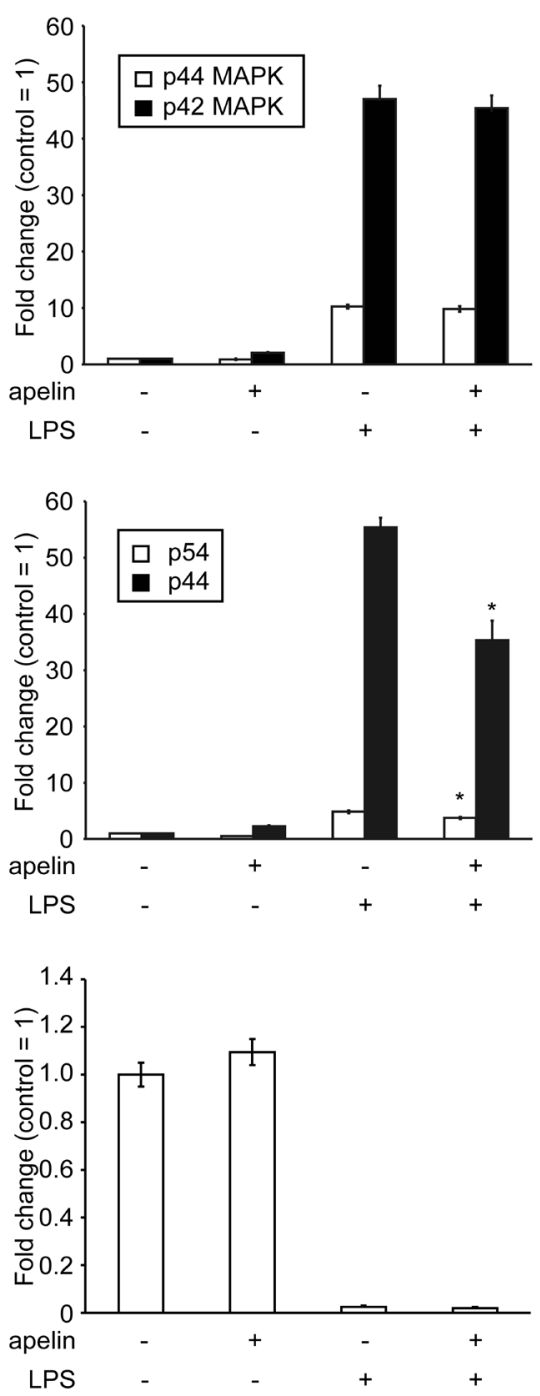

Figure 4. Effect of apelin on LPS induced MAPK phosphorylation in J774.1 cells. Cells were pretreated with or without [Pyr-1]-apelin-13 $(1 \mu \mathrm{M})$ overnight and then stimulated with LPS (10 ng/mL) for $30 \mathrm{~min}$. Whole lysates were immunoblotted with anti-phospho-p38 MAPK, anti-p38 MAPK antibodies (a), anti-phospho-Erk1/2, anti-Erk1/2 antibodies (b), anti-phospho-SAPK/JNK and anti-SAPK/JNK antibodies (c), anti-IкB $\alpha$ antibody (d). The aliquots used contained equivalent amounts of protein from the samples, which was verified by Western blotting for $\beta$-actin. The intensity of the band was quantified and calculated as the ratio of target protein to $\beta$-actin. The data shown represent the mean \pm SD of three independent experiments. ${ }^{*} P<0.05$ (apelin-/LPS+ vs apelin+/LPS + ), two-tailed Students $t$-test. 


\subsection{Effect of Apelin on LPS-Induced Phosphorylation of p38 MAPK and JNK in J774.1 Cells}

We examined whether [Pyr1]-apelin-13 inhibited LPS-stimulated intracellular signal transduction in J774.1 cells. Since LPS stimulation is known to activate MAPKs and NF-kB, phosphorylation of MAPKs and degradation of

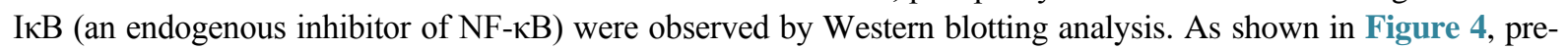
treatment with [Pyr1]-apelin-13 significantly reduced p38 MAPK and JNK, but not ERK phosphorylation or degradation of IкB in LPS-stimulated J774.1 cells. These data suggest that [Pyr1]-apelin-13 inhibited LPS-induced cell signalling in macrophages.

\section{Discussion}

In the present study, we demonstrated that pretreatment with [Pyr1]-apelin-13 diminished LPS-induced proinflammatory cytokine expression in the murine macrophage-like cell line, J774.1 cells. In addition, the phosphorylation of p38 MAPK and JNK induced by LPS decreased in [Pyr1]-apelin-13-treated J774.1 cells. To the best of our knowledge, this is the first report that the apelin peptide family has anti-inflammatory effects against bacterial LPS stimulation in macrophages.

Early studies on apelin suggested that it plays a role in the immune system. Apelin-36 and the more effective apelin-13 were found to suppress the production of interferon- $\gamma$, IL-2 and IL-4 in mouse spleen cells activated by CD3 cross-linking [15]. Since peripheral blood mononuclear cells treated with phytohaemagglutinin and IL-2 express APJ, the apelinergic system likely plays a role in immune activity [17]. In the present study, J774.1 and RAW 264.7 cells expressed APJ, suggesting that apelin has an immune function in macrophages. Previous studies also observed APJ expression in these two cell lines, which was consistent with our results [18]. Apelin administration has been reported to reduce levels of the 3T3-L1 adipocyte-driven pro-inflammatory adipokine acylation stimulating protein, which induces macrophage filtration in adipose tissue [19]. Apelin-13 promotes cholesterol efflux by enhancing the expression of ATP-binding cassette transporter A1 in foam cells, which suggests that apelin has an anti-atherogenic effect [20]. Considering these protective properties of apelin, overproduction of apelin in obese individuals may be an adaptive response before the onset of obesity-related disorders such as mild chronic inflammation, cardiovascular dysfunction and type 2 diabetes [21] [22].

While apelin pretreatment lowered LPS-induced IL-1 $\beta$ and IL-6 production, we observed no significant effect of apelin alone on cytokine production in J774.1 cells. Previous studies, however, have demonstrated that apelin reduced IL-6 and MCP-1 production in J774A.1 cells [18]. Although different media or serum can affect the results, the reason for the discrepancy between the two reports remains unclear.

Toll-like receptors are large family members of type 1 transmembrane receptors that play an important role in the innate immune system. LPS activates the TLR4-mediated signalling pathway and leads to the activation of MAPKs to regulate the release of pro-inflammatory cytokines [5]. In addition, stimulation of murine macrophages by LPS induces the phosphorylation of ERK1/2, JNK and p38 MAPKs, which activates the expression of pro-inflammatory cytokines [23] [24]. In this study, we showed that apelin pretreatment suppressed LPS-induced JNK and p38 MAPK phosphorylation, suggesting that apelin has anti-inflammatory effects.

Adiponectin has been shown to possess anti-inflammatory properties against LPS stimulation in macrophages [25]-[27]. Both types of adiponectin isoforms, full-length (flAcrp) and globular form (gAcrp), suppressed LPSinduced MAPKs and NFKB activation in macrophages. Although LPS-stimulated TNF- $\alpha$ mRNA transcription is directly suppressed by inactivation of NF-kB and AP1 via the adiponectin receptor, transcription is also indirectly suppressed in a gAcrp-induced IL-10-dependent manner at a later stage [27]. Recent studies demonstrated that the anti-inflammatory effects of gAcrp mediate IL-10 and haeme oxygenase-1-dependent pathways [28], whereas the effects of flAcrp are independent of IL-10 and are inducible by M2 polarisation in macrophages [25] [29]. In our experiments, apelin alone did not significantly increase IL-10 mRNA expression in J774.1 cells and RAW 264.7 cells (data not shown). Further experiments are need to clarify that the molecular mechanisms of apelin in innate immunity remain unclear.

\section{Conclusion}

In conclusion, we demonstrated that [Plyr1]-apelin-13 has anti-inflammatory activity by inhibiting p38 MAPK and JNK, and reducing IL-1 $\beta$ and IL-6 production in LPS-stimulated J774.1 cells. 


\section{References}

[1] Pitkin, S.L., Maguire, J.J., Bonner, T.I. and Davenport, A.P. (2010) International Union of Basic and Clinical Pharmacology. LXXIV. Apelin Receptor Nomenclature, Distribution, Pharmacology, and Function. Pharmacological Review, 62, 331-342. http://dx.doi.org/10.1124/pr.110.002949

[2] O’Carroll, A.M., Lolait, S.J., Harris, L.E. and Pope, G.R. (2013) The Apelin Receptor APJ: Journey from an Orphan to a Multifaceted Regulator of Homeostasis. Journal of Endocrinology, 219, R13-R35. http://dx.doi.org/10.1530/JOE-13-0227

[3] Kalin, R.E., Kretz, M.P., Meyer, A.M., Kispert, A., Heppner, F.L. and Brandli, A.W. (2007) Paracrine and Autocrine Mechanisms of Apelin Signaling Govern Embryonic and Tumor Angiogenesis. Developmental Biology, 305, 599-614. http://dx.doi.org/10.1016/j.ydbio.2007.03.004

[4] Carpene, C., Dray, C., Attane, C., Valet, P., Portillo, M.P., Churruca, I., Milagro, F.I. and Castan-Laurell, I. (2007) Expanding Role for the Apelin/APJ System in Physiopathology. Journal of Physiology and Biochemistry, 63, 359-373. http://dx.doi.org/10.1007/BF03165767

[5] Medhurst, A.D., Jennings, C.A., Robbins, M.J., Davis, R.P., Ellis, C., Winborn, K.Y., Lawrie, K.W., Hervieu, G., Riley, G., Bolaky, J.E., Herrity, N.C., Murdock, P. and Darker, J.G. (2003) Pharmacological and Immunohistochemical Characterization of the APJ Receptor and Its Endogenous Ligand Apelin. Journal of Neurochemistry, 84, 1162-1172. http://dx.doi.org/10.1046/j.1471-4159.2003.01587.x

[6] O’Carroll, A.M., Selby, T.L., Palkovits, M. and Lolait, S.J. (2000) Distribution of mRNA Encoding B78/apj, the Rat Homologue of the Human APJ Receptor, and Its Endogenous Ligand Apelin in Brain and Peripheral Tissues. Biochimica et Biophysica Acta, 1492, 72-80. http://dx.doi.org/10.1016/S0167-4781(00)00072-5

[7] Falcao-Pires, I., Ladeiras-Lopes, R. and Leite-Moreira, A.F. (2010) The Apelinergic System: A Promising Therapeutic Target. Expert Opinion on Therapeutic Targets, 14, 633-645. http://dx.doi.org/10.1517/14728221003752743

[8] Boucher, J., Masri, B., Daviaud, D., Gesta, S., Guigne, C., Mazzucotelli, A., Castan-Laurell, I., Tack, I., Knibiehler, B., Carpene, C., Audigier, Y., Saulnier-Blache, J.S. and Valet, P. (2005) Apelin, a Newly Identified Adipokine Up-Regulated by Insulin and Obesity. Endocrinology, 146, 1764-1771. http://dx.doi.org/10.1210/en.2004-1427

[9] Ishida, J., Hashimoto, T., Hashimoto, Y., Nishiwaki, S., Iguchi, T., Harada, S., Sugaya, T., Matsuzaki, H., Yamamoto, R., Shiota, N., Okunishi, H., Kihara, M., Umemura, S., Sugiyama, F., Yagami, K., Kasuya, Y., Mochizuki, N. and Fukamizu, A. (2004) Regulatory Roles for APJ, a Seven-Transmembrane Receptor Related to Angiotensin-Type 1 Receptor in Blood Pressure in Vivo. The Journal of Biological Chemistry, 279, 26274-26279. http://dx.doi.org/10.1074/jbc.M404149200

[10] Salcedo, A., Garijo, J., Monge, L., Fernandez, N., Luis Garcia-Villalon, A., Sanchez Turrion, V., Cuervas-Mons, V. and Dieguez, G. (2007) Apelin Effects in Human Splanchnic Arteries. Role of Nitric Oxide and Prostanoids. Regulatory Peptides, 144, 50-55. http://dx.doi.org/10.1016/j.regpep.2007.06.005

[11] Sorli, S.C., van den Berghe, L., Masri, B., Knibiehler, B. and Audigier, Y. (2006) Therapeutic Potential of Interfering with Apelin Signalling. Drug Discovery Today, 11, 1100-1106. http://dx.doi.org/10.1016/j.drudis.2006.10.011

[12] Zhu, S., Sun, F., Li, W., Cao, Y., Wang, C., Wang, Y., Liang, D., Zhang, R., Zhang, S., Wang, H. and Cao, F. (2011) Apelin Stimulates Glucose Uptake through the PI3K/Akt Pathway and Improves Insulin Resistance in 3T3-L1 Adipocytes. Molecular and Cellular Biochemistry, 353, 305-313. http://dx.doi.org/10.1007/s11010-011-0799-0

[13] Castan-Laurell, I., Vitkova, M., Daviaud, D., Dray, C., Kovacikova, M., Kovacova, Z., Hejnova, J., Stich, V. and Valet, P. (2008) Effect of Hypocaloric Diet-Induced Weight Loss in Obese Women on Plasma Apelin and Adipose Tissue Expression of Apelin and APJ. European Journal of Endocrinology, 158, 905-910. http://dx.doi.org/10.1530/EJE-08-0039

[14] Li, L., Yang, G., Li, Q., Tang, Y., Yang, M., Yang, H. and Li, K. (2006) Changes and Relations of Circulating Visfatin, Apelin, and Resistin Levels in Normal, Impaired Glucose Tolerance, and Type 2 Diabetic Subjects. Experimental and Clinical Endocrinology \& Diabetes, 114, 544-548. http://dx.doi.org/10.1055/s-2006-948309

[15] Habata, Y., Fujii, R., Hosoya, M., Fukusumi, S., Kawamata, Y., Hinuma, S., Kitada, C., Nishizawa, N., Murosaki, S., Kurokawa, T., Onda, H., Tatemoto, K. and Fujino, M. (1999) Apelin, the Natural Ligand of the Orphan Receptor APJ, Is Abundantly Secreted in the Colostrum. Biochimica et Biophysica Acta, 1452, 25-35. http://dx.doi.org/10.1016/S0167-4889(99)00114-7

[16] Horiuchi, Y., Fujii, T., Kamimura, Y. and Kawashima, K. (2003) The Endogenous, Immunologically Active Peptide Apelin Inhibits Lymphocytic Cholinergic Activity during Immunological Responses. Journal of Neuroimmunology, 144, 46-52.

[17] Choe, H., Farzan, M., Konkel, M., Martin, K., Sun, Y., Marcon, L., Cayabyab, M., Berman, M., Dorf, M.E., Gerard, N., Gerard, C. and Sodroski, J. (1998) The Orphan Seven-Transmembrane Receptor Apj Supports the Entry of Primary T-Cell-Line-Tropic and Dualtropic Human Immunodeficiency Virus Type 1. Journal of Virology, 72, 6113-6118. 
[18] Leeper, N.J., Tedesco, M.M., Kojima, Y., Schultz, G.M., Kundu, R.K., Ashley, E.A., Tsao, P.S., Dalman, R.L. and Quertermous, T. (2009) Apelin Prevents Aortic Aneurysm Formation by Inhibiting Macrophage Inflammation. American Journal of Physiology-Heart and Circulatory Physiology, 296, H1329-H1335. http://dx.doi.org/10.1152/ajpheart.01341.2008

[19] Lu, H., Gauvreau, D., Tom, F.Q., Lapointe, M., Luo, X.P. and Cianflone, K. (2013) Inflammatory Markers and Adipokines Alter Adipocyte-Derived ASP Production through Direct and Indirect Immune Interaction. Experimental and Clinical Endocrinology \& Diabetes, 121, 194-200. http://dx.doi.org/10.1055/s-0032-1333231

[20] Liu, X.Y., Lu, Q., Ouyang, X.P., Tang, S.L., Zhao, G.J., Lv, Y.C., He, P.P., Kuang, H.J., Tang, Y.Y., Fu, Y., Zhang, D.W. and Tang, C.K. (2013) Apelin-13 Increases Expression of ATP-Binding Cassette Transporter A1 via Activating Protein Kinase C Alpha Signaling in THP-1 Macrophage-Derived Foam Cells. Atherosclerosis, 226, 398-407. http://dx.doi.org/10.1016/j.atherosclerosis.2012.12.002

[21] Lago, F., Dieguez, C., Gomez-Reino, J. and Gualillo, O. (2007) Adipokines as Emerging Mediators of Immune Response and Inflammation. Nature Clinical Practice Rheumatology, 3, 716-724. http://dx.doi.org/10.1038/ncprheum0674

[22] Falcao-Pires, I., Castro-Chaves, P., Miranda-Silva, D., Lourenco, A.P. and Leite-Moreira, A.F. (2012) Physiological, Pathological and Potential Therapeutic Roles of Adipokines. Drug Discovery Today, 17, 880-889. http://dx.doi.org/10.1016/j.drudis.2012.04.007

[23] Chi, H., Barry, S.P., Roth, R.J., Wu, J.J., Jones, E.A., Bennett, A.M. and Flavell, R.A. (2006) Dynamic Regulation of Pro- and Anti-Inflammatory Cytokines by MAPK Phosphatase 1 (MKP-1) in Innate Immune Responses. Proceedings of the National Academy of Sciences of the United States of America, 103, 2274-2279. http://dx.doi.org/10.1073/pnas.0510965103

[24] Chan, E.D. and Riches, D.W. (2001) IFN-Gamma + LPS Induction of iNOS Is Modulated by ERK, JNK/SAPK, and p38(mapk) in a Mouse Macrophage Cell Line. American Journal of Physiology. Cell Physiology, 280, C441-C450.

[25] Folco, E.J., Rocha, V.Z., Lopez-Ilasaca, M. and Libby, P. (2009) Adiponectin Inhibits Pro-Inflammatory Signaling in Human Macrophages Independent of Interleukin-10. Journal of Biological Chemistry, 284, 25569-25575. http://dx.doi.org/10.1074/jbc.M109.019786

[26] Kamio, N., Akifusa, S., Yamaguchi, N., Nonaka, K. and Yamashita, Y. (2009) Anti-Inflammatory Activity of a Globular Adiponectin Function on RAW 264 Cells Stimulated by Lipopolysaccharide from Aggregatibacter actinomycetemcomitans. FEMS Immunology \& Medical Microbiology, 56, 241-247. http://dx.doi.org/10.1111/j.1574-695X.2009.00573.x

[27] Park, P.H., Huang, H., McMullen, M.R., Mandal, P., Sun, L. and Nagy, L.E. (2008) Suppression of LipopolysaccharideStimulated Tumor Necrosis Factor-Alpha Production by Adiponectin Is Mediated by Transcriptional and Post-Transcriptional Mechanisms. Journal of Biological Chemistry, 283, 26850-26858. http://dx.doi.org/10.1074/jbc.M802787200

[28] Mandal, P., Park, P.H., McMullen, M.R., Pratt, B.T. and Nagy, L.E. (2010) The Anti-Inflammatory Effects of Adiponectin Are Mediated via a Heme Oxygenase-1-Dependent Pathway in Rat Kupffer Cells. Hepatology, 51, 1420-1429. http://dx.doi.org/10.1002/hep.23427

[29] Mandal, P., Pratt, B.T., Barnes, M., McMullen, M.R. and Nagy, L.E. (2011) Molecular Mechanism for AdiponectinDependent M2 Macrophage Polarization: Link between the Metabolic and Innate Immune Activity of Full-Length Adiponectin. Journal of Biological Chemistry, 286, 13460-13469. http://dx.doi.org/10.1074/jbc.M110.204644 